\title{
Hyperechoic Rim in a Follicular Variant of Papillary Thyroid Carcinoma - A Rare Ultrasonographic Feature
}

\author{
Yavor Assyov $^{1 *}$, Antoaneta Gateva1, Radina Ivanova² and Zdravko Kamenov ${ }^{1}$ \\ ${ }^{1}$ Department of Endocrinology, Alexandrovska University Hospital, Medical University-Sofia, Bulgaria \\ ${ }^{2}$ Laboratory of Clinical Pathology, University Hospital of Endocrinology, Medical University-Sofia, Bulgaria
}

\begin{abstract}
We present a case of a follicular variant of papillary thyroid carcinoma (PTC) with an uncommon sonographic feature-hyperechoic rim. A 24-year old female was referred to our department for an incidentally discovered nodule in the left lobe of the thyroid gland with an accompanying neck lymphadenomegaly. Ultrasound revealed a $1-\mathrm{cm}$ hypoechoic nodule with a hyperechoic periphery with peripheral vascularity. The cytological finding was suspicious for PTC. Histology confirmed the suspected diagnosis. Hyperechoic rim is an uncommon ultrasound feature of thyroid nodules. A potential association with follicular variant of PTC needs to be explored.
\end{abstract}

Keywords: Papillary thyroid carcinoma; Hyperechoic rim; Thyroid ultrasound

\section{Introduction}

Thyroid nodules are very common in the general population and the majority of them are benign [1]. It is estimated that approximately $3 \%$ to $7 \%$ of the population have a palpable nodule and this prevalence might increase to $70 \%$ if patients are screened by an ultrasound [2]. Circa $5 \%$ of ultrasound-detected thyroid nodules are malignant, rising up to $33 \%$ if the nodule was discovered by a PET scan $[3,4]$. Papillary thyroid carcinoma (PTC) is the most common thyroid malignancy, representing approximately $70 \%$ to $80 \%$ of all cases [5]. Histologically, it is composed of multifocal papillary and follicul ar elements [6]. Its prognosis is generally favorable as it tends to grow and metastasize slowly [6].

The follicular variant of papillary thyroid carcinoma (FVPTC) is the most common variant of PTC, representing 30\% of all PTCs [7]. It is more common in women with a 3.6:1 female to male ratio with mean age at presentation being the $5^{\text {th }}$ decade [8]. Despite the variations based on presence or absence of invasion, the overall clinical outcome tends to be excellent for these tumors [9]. Two main types of FVPTC exist: encapsulated and invasive follicular variants, while the diffuse and macrofollicular variants are exceedingly rare $[10,11]$. By definition, follicular architecture must be the main finding, on the background of nuclear features of a PTC. Papillary structures are required to be $<1 \%$ of the volume, while necroses, increased mitoses and psammoma bodies are usually absent [12].

Ultrasound (US) is widely considered the first-line diagnostic tool for the evaluation of thyroid nodules because of its sensitivity and convenience [13]. Albeit no single US criterion of the thyroid nodule can distinguish between benign and malignant with $100 \%$ reliability, some have been identified as predictors of thyroid malignancy. These include marked hypo-echoic characteristics, solid, taller-than-wide shape, presence of microcalcifications and irregular margins [14-16]. The "halo" sign as an ultrasound feature is described as a complete or partial hypo-echoic margin that surrounds the periphery of a mass and can be found in mostly benign nodules. It has been proposed to be helpful in distinguishing benign from malignant thyroid nodules $[13,17]$. Furthermore, the absence of the halo was proposed as one of the patterns, predictive of malignancy with a specificity of $77 \%$ and sensitivity of $67 \%$ [18].

However, the presence of a hyperechoic margin of a hypoechoic thyroid nodule as an ultrasound feature has been largely ignored in the literature [19]. We present a case with a follicular variant of papillary thyroid carcinoma with lymph node metastases with such ultrasonographic feature.

\section{Case Report}

Our patient was a 24-year-old female who was referred to our Department for an incidentally discovered thyroid nodule. She denied having compression symptoms or those of thyroid hormone excess. Serum anti-thyroglobulin antibodies, thyroid-peroxidase antibodies and calcitonin were within the reference ranges.

Ultrasound revealed an oval hypoechoic lesion in the left lobe of the thyroid with the dimensions of $10 \mathrm{~mm} \times 12 \mathrm{~mm} \times 9 \mathrm{~mm}$ with microcalcifications present and type I blood-flow. It was surrounded by a massive hyperechoic periphery, suggestive of fibrosis, with irregular margins (Figure 1). Ipsilateral lymph nodes with similar US characteristic were also present- level IV- with dimensions going up to 2 $\mathrm{cm}$ longitudinally (Figure 2). Fine-needle aspiration biopsy (FNA) of the thyroid nodule revealed atypical follicular cell proliferations, suspicious for PTC (Bethesda V, Figure 3). The cytological smears showed moderate cellularity, including some follicular- and papillary-like clusters of overlapping cells but typical intranuclear inclusions and nuclear grooves were present only in single nuclei. FNA of the aforementioned lymph node found one group of atypical cells, suggestive for thyroid follicular origin but the thyroglobulin (Tg) concentration in the wash-out fluid was higher compared to the serum Tg level- $71.04 \mathrm{ng} / \mathrm{ml}$ and $30.28 \mathrm{ng} /$ $\mathrm{ml}$, respectively.

The patient was referred for surgical treatment where total thyroidectomy with a radical left neck lymph node dissection was performed. Histological evaluation revealed an infiltrative FVPTC, with predominant micro-follicular growth pattern and nuclear features of the cells characteristic for PTC, but also some fibrous septa and psammoma bodies in the vicinity of the tumor (Figure 4). Tumor metastases in

*Corresponding author: Yavor Assyov, Department of Endocrinology, Alexandrovska University Hospital, Medical University-Sofia, Bulgaria, Tel: 00359887451961; E-mail: y.assyov@medical-arts.bg

Received October 21, 2017; Accepted November 14, 2017; Published November 20, 2017

Citation: Assyov Y, Gateva A, Ivanova R, Kamenov Z (2017) Hyperechoic Rim in a Follicular Variant of Papillary Thyroid Carcinoma-A Rare Ultrasonographic Feature. J Clin Case Rep 7: 1044. doi: 10.4172/2165-7920.10001044

Copyright: @ 2017 Assyov Y, et al. This is an open-access article distributed under the terms of the Creative Commons Attribution License, which permits unrestricted use, distribution, and reproduction in any medium, provided the original author and source are credited. 
two of the eight extirpated lymph nodes were also found. The final histopathological staging was pT1N1aMO. Postoperatively, the patient was referred for a thyroid remnant ablation of I-131 with Tg of 0.861 $\mathrm{ng} / \mathrm{ml}$ and TSH of $35.76 \mathrm{mU} / \mathrm{l}$. No areas of intense radiofixation in the thyroid bed, as well as in the neck lymph nodes were reported on SPECT-CT. On the sixth postoperative month Tg concentration was less than $0.01 \mathrm{ng} / \mathrm{ml}$.

\section{Discussion}

The presence of a halo sign is a frequent finding on a thyroid nodule.

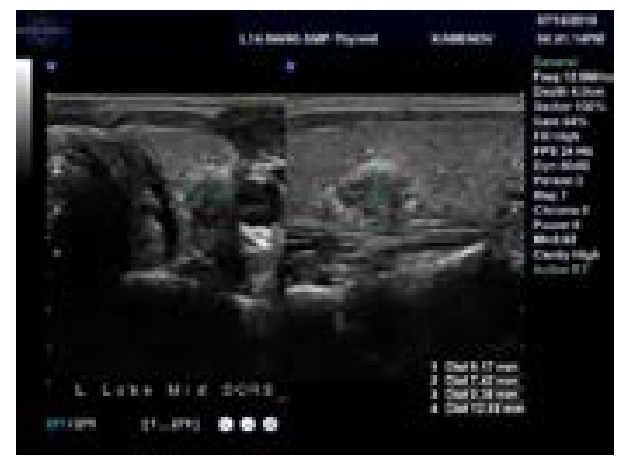

Figure 1: Ultrasound appearance of the thyroid nodule in our case.

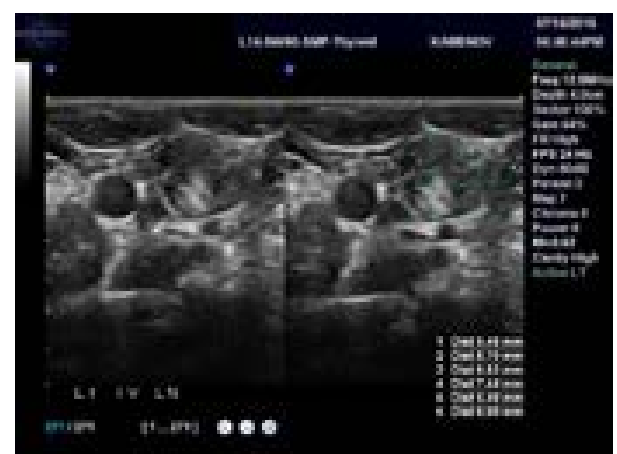

Figure 2: Ultrasound appearance of the suspected metastatic lymph nodes on which FNA and thyroglobulin wash-out was performed.

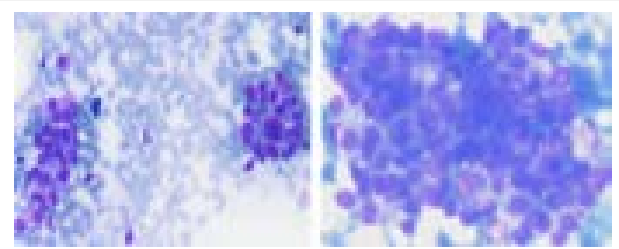

Figure 3: Cytological findings on fine-needle aspiration biopsy of thyroid nodule (x80, MGG).
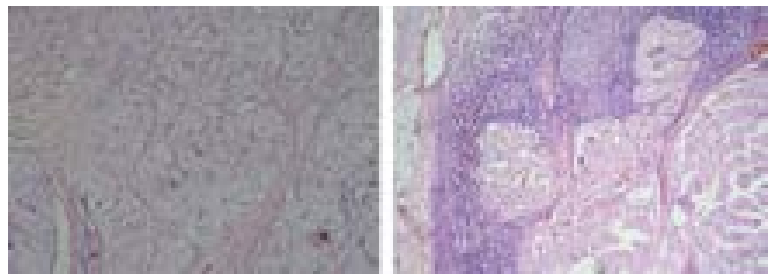

Figure 4: Histological findings of the thyroid nodule and metastatic lymph node $(\mathrm{x} 40, \mathrm{HE})$.
It is generally defined as a peripheral hypoechoic rim around a nodule, which has been suggested to represent either a capsule or compressed thyroid tissue or vessels [20]. It is widely accepted as a benign sonographic feature $[13,17]$. The significance of the hyperechoic rim in thyroid nodules, however, has been widely ignored. A single Chinese study reported a series of 228 histologically proven thyroid nodules (137 malignant and 91 benign) in which the presence of this feature is evaluated. The authors have found that the hyperechoic rim was present in approximately one-third of the papillary thyroid carcinomas and had a high specificity of $94.5 \%$ but low sensitivity (31.39\%) in predicting malignancy $(\mathrm{p}<0.05)$. The malignant lesions with this ultrasonographic feature had a boundary zone of mixed structure comprising apparent fibrous stroma bands or dense collagenous border with a mixed population of cancerous cells on microscopic evaluation. The authors concluded that the presence of this particular US feature could be a new criterion for the differential diagnosis of thyroid nodules [19]. The variants of the papillary carcinomas, discussed in the aforementioned article, however, have not been discussed. No study in the literature has reported an association between hyperechoic rims and follicular variant of PTC as our case. We hypothesize of a potential such association based on the similar percentage of subjects exhibiting this US feature in the Chinese study (30\%) as is the reported incidence of FVPTC of PTC cases.

It is worth noting that this particular US feature is very similar in breast lesions, where it is suggested to be key in the identification of breast cancer [21]. Histopathological studies have shown that hyperechoic halos represent a speculated edge and invading margin of the malignant breast lesion under microscopy [19]. It has been suggested that this US feature may be caused by heterogeneous components, which are smaller than the sound wave which results in a backscattering and a band with a higher acoustic impedance difference, as seen on US. This phenomenon, however, was not as apparent in the thyroid as in breast lesions because the former has no fatty tissue and a less mixed histologic structure. It could be that the hyperechoic rim may be one specific type of irregular margin seen in papillary carcinomas [19].

\section{Conclusion}

Hyperechoic rim as an ultrasonographic feature of thyroid nodules could be a new criterion for the differentiation of PTC. The authors hypothesize that this feature could be associated with follicular variant of PTC.

\section{References}

1. Knox MA (2013) Thyroid nodules. Am Fam Physician 88: 193-196.

2. Cooper DS, Doherty GM, Haugen BR, Kloos RT, Lee SL, et al (2010) For the American Thyroid Association (ATA) Guidelines taskforce on thyroid nodules and differentiated thyroid cancer. Revised american thyroid association management guidelines for patients with thyroid nodules and differentiated thyroid Cancer: the American Thyroid Association (ATA) guidelines taskforce on CLINICAL8 I American Health and Drug Benefits. Thyroid 19: 1167-1214.

3. Corso C, Gomez X, Sanabria A, Vega V, Dominguez LC, et al. (2014) Tota thyroidectomy versus hemithyroidectomy for patients with follicular neoplasm. A cost-utility analysis. Int J Surg 12: 837-842.

4. Welker MJ, Orlov D (2003) Thyroid nodules. Am Fam Physician 67: 559-566.

5. https://www.cancer.gov/types/thyroid/patient/thyroid-treatment-pdq

6. https://medlineplus.gov/ency/article/001213.htm

7. Daniels GH (2011) What if many follicular variant papillary thyroid carcinomas are not malignant? A review of follicular variant papillary thyroid carcinoma and a proposal for a new classification. Endocr Pract 17: 768e87.

8. Thompson LD (2016) Ninety-four cases of encapsulated follicular variant of papillary thyroid carcinoma: A name change to noninvasive follicular thyroid 
Citation: Assyov Y, Gateva A, Ivanova R, Kamenov Z (2017) Hyperechoic Rim in a Follicular Variant of Papillary Thyroid Carcinoma- A Rare Ultrasonographic Feature. J Clin Case Rep 7: 1044. doi: 10.4172/2165-7920.10001044

neoplasm with papillary-like nuclear features would help prevent overtreatment. Mod Pathol 29: 698-707.

9. LiVolsi VA, Albores-Saavedra J, Asa SL (2004) Papillary carcinoma. In: DeLellis RA, Lloyd RV, Heitz PU, Eng C (eds). Pathology and genetics of tumours of endocrine organs. (3rd edn). IARC Press, Lyon, France.

10. Ivanova R, Soares P, Castro P, Simões MS (2002) Diffuse (or multinodular) follicular variant of papillary thyroid carcinoma: A clinicopathologic and immunohistochemical analysis of ten cases of an aggressive form of differentiated thyroid carcinoma. Virchows Arch 440: 418e24.

11. Lloyd RV, Buehler D, Khanafshar E (2011) Papillary thyroid carcinoma variants. Head Neck Pathol 5: 51e6.

12. Rivera M, Ricarte-Filho J, Patel S, Tuttle M, Shaha A, et al. (2010) Encapsulated thyroid tumors of follicular cell origin with high grade features (high mitotic rate/ tumor necrosis): A clinicopathologic and molecular study. Hum Pathol 41: tumor nec

13. Niedziela M (2014) Thyroid nodules. Best Pract Res Clin Endocrinol Metab 28: $245-277$

14. Cappelli C (2006) Thyroid nodule shape suggests malignancy. Eur J Endocrino 155: 27-31.

15. Yoon DY, Lee JW, Chang SK, Choi CS, Yun EJ, et al. (2007) Peripheral calcification in thyroid nodules: Ultrasonographic features and prediction of malignancy. J Ultrasound Med 26: 1349-1355.

16. Kim EK, Park CS, Chung WY, Oh KK, Kim DI, et al. (2002) New sonographic criteria for recommending fine-needle aspiration biopsy of nonpalpable solid nodules of the thyroid. AJR Am J Roentgenol 178: 687-691.

17. Alper O, Bulent C, Hayede M, Erturk SM, Peker K, et al. (2009) Ultrasonographic features of benign nodules, follicular lesions and malignant nodules in the thyroid diagnosed mainly by fine needle aspiration biopsy. J Med Ultrasound 17: $200-206$.

18. Rago T, Vitti P, Chiovato L, Mazzeo S (1998) Role of conventional ultrasonography and color flow-Doppler sonography in predicting malignancy in 'cold' thyroid nodules. Eur $\mathrm{J}$ Endocrinol 138: 41-46.

19. Dong Y, Zhan W, Zhou J, Song L, Ni XF, et al. (2016) Echoic rim in thyroid nodules: A new ultrasonographic feature for malignancy prediction. Ultrasound Med Biol 42: 2123-2129.

20. Mcivor NP, Freeman JL, Salem S (1993) Ultrasonography of the thyroid and parathyroid glands. ORL J Oto-rhino-laryngol. Relat Spec 55: 303-308.

21. Tamaki K, Sasano H, Ishida T, Ishida K, Miyashita M, et al. (2010) The correlation between ultrasonographic findings and pathologic features in breast disorders. Jpn J Clin Oncol 40: 905-912. 